\title{
Keragaman Jenis Anggrek Epifit Sebagai Objek Wisata Alam Di Kawasan TWA Gunung Kelam Kabupaten Sintang
}

\author{
Antonius \\ Fakultas Pertanian Universitas Kapuas Sintang \\ Email : anton1975_gurung@yahoo.co.id
}

\begin{abstract}
Abstrak: Gunung Kelam sebagai salah satu destinasi wisata alam yang paling banyak dikunjungi oleh wisatawan diantara berbagai objek wisata yang ada di Kabupaten Sintang. Ciri khas Gunung Kelam yang terbentuk dari batu tunggal serta keanekaragaman flora yang tinggi merupakan daya Tarik wisata. Penelitian ini dilakukan untuk mengeksplorasi dan menginventarisasi anggrek di kawasan Taman Wisata Alam Gunung Kelam, serta mengetahui keanekaragaman jenis anggrek. Metode penelitian adalah eksplorasi seluruh kawasan. Hasil penelitian ditemukan 16 (empat belas) jenis anggrek, antara lain adalah : Apendicula $s p$, Arundina graminifolia (Anggrek bambu), Anggrek kebutan (Ascocentrum miniatum), Bulbophyllum auratum (Lindl) Rchb. F, Anggrek Joget (Bromheadia finlaysoniana (Lindl) Rchb. F.), Coelogyne sp, Cymbidium finlaysonianum (Anggrek Lidah Ular), Cymbidium sp, Dendrobium crumenatum Swartz (Anggrek Merpati), Dendrobium secundum (Anggrek sikat), Dendrobium Smithianum Schltr, Dendrobium sp, Grammotophylum speciosum (Anggrek tebu), Vanda sp, Vanda tricolor dan satu jenis yang belum diketahui namanya.
\end{abstract}

Kata Kunci: Keanekaragaman Jenis, Anggrek, Wisata Alam

\section{PENDAHULUAN}

Kalimantan sebagai salah satu pulau terbesar di Indonesia mempunyai kawasan hutan yang luas dan merupakan habitat dari beragam flora dan fauna, diantaranya diperkirakan sekitar 2.500-3.000 jenis anggrek (Irawati, 2002). Menurut Effendi et al (2019) bahwa anggrek Borneo yang telah dilaporkan berjumlah sekitar 1411 jenis, yang ditemukan pada berbagai tipe habitat, mulai dari daerah pesisir sampai ke daerah pegunungan. Informasi dan kegiatan eksplorasi tentang flora anggrek di Kalimantan Barat, khususnya di berbagai kawasan hutan di Kabupaten Sintang masih banyak belum tersentuh sehingga informasi tentang keanekaragaman jenis anggrek efifit yang terdapat didalamnya masih sangat terbatas. Salah satunya adalah di kawasan hutan Taman Wisata Alam Gunung Kelam. 
Taman Wisata Alam Gunung

Kelam saat ini menjadi pusat pengembangan kegiatan wiata alam yang paling banyak dikunjungi oleh wisatawan, baik lokal maupun wisatawan mancanegera oleh karena keunikan alamnya berupa batuan tunggal terbesar di dunia (Lestari, et al. 2019) serta memiliki keanekaragaman jenis flora yang tinggi. Lebih lanjut dinyatajan bahwa keunikan TWA Bukit Kelam lainnya yaitu terdapat tumbuhan endemik seperti kantong semar (Nepenthes clipeata) dan anggrek hitam (Coelogyn pandurata) yang hampir punah. Sebagai objek wisata, TWA Gunung Kelam memiliki daya Tarik wisata yang tinggi, sehingga rawan akan pencurian berbagai sumber genetik dari berbagai jenis tumbuhan endemik oleh para penggemar tumbuhan langka dan hobby mengkoleksinya. Untuk mengantisipasi punahnya berbagai jenis tumbuhan langka dan endemik yang dapat dikategorikan sebagai flagship spesies TWA Gunung Kelam, maka perlu dilakukan inventarisasi berbagai jenis flora, khususnya terhadap jenis anggrek efifit.
Salah satu kawasan dengan pengkoleksian anggrek yang masih sedikit adalah kawasan TWA Bukit Kelam. TWA Bukit Kelam ditetapkan berdasarkan SK Menhut No. 594/Kpts-II/1992 tanggal 6 Juni 1992 dengan luas \pm 520 Ha. Kawasan ini termasuk dalam wilayah Kecamatan Kelam Permai, dengan

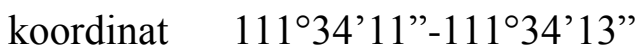
BT dan $0^{\circ} 05^{\prime} 25^{\prime \prime}-0^{\circ} 05^{\prime} 27^{\prime \prime} \quad$ LU (Ariyanti dan Pa'i, 2008). Topografi kawasan ini datar sampai berbukit dengan jenis tanah dominan podsolik merah kuning. Bagian tengah Bukit Kelam merupakan hutan hujan tropis yang kondisinya tidak primer lagi akibat kebakaran hutan tahun 1997 (Kayoman, 2005).

Penelitian terkait anggrek di TWA Gunung Kelam pernah dilakukan sebelumnya oleh Lestari et al (2019). Penelitian berhasil merekam sebanyak 11 jenis anggrek teresterial di TWA Gunung Kelam yang dilakukan di seluruh blok. Pada penelitian ini akan dilakukan pengamatan khusus untuk blok pemanfaatan, karena blok ini rawan terhadap pencurian dan pengkoleksian anggrek oleh para pengunjung. 


\section{METODE PENELITIAN}

Penelitian keanekaragaman jenis anggrek epifit dilakukan di Taman Wisata Alam Gunung Kelam dari tanggal 10 Februari sampai dengan tanggal 21 Maret 2020. Penelitian dilakukan di blok kawasan TWA Gunung Kelam, yakni khusus di blok pemanfaatan.

Pengambilan sampel dilakukan dengan metode Visual Encounter Survey (VES) dengan batasan sampel yang diambil ialah tumbuhan anggrek yang sedang berbunga atau yang memiliki karakter kunci identifikasi. Selain itu dilakukan juga metode wawancara dengan warga sekitar dan eksplorasi untuk mencari anggrek hasil wawancara. Anggrek yang ditemukan diambil fotohabitus, daun, dan perbungaan terlebih dahulu untuk dokumentasi dan proses identifikasi. Selanjutnya anggrek yang ditemukan dilakukan diidentifikasi menggunakan buku identifikasi jenis anggrek.

\section{HASIL DAN PEMBAHASAN}

Sebanyak 16 spesies anggrek yang tergolong ke dalam 9 genus ditemukan di Taman Wisata Alam (TWA) Gunung Kelam Kecamatan
Kelam Permai Kabupaten Sintang. Terdapat 8 anggrek epifit, 8 anggrek teresterial (Tabel 1). Salah satu contoh anggrek dengan tipe hidup epifit ialah Appendicula sp, merupakan anggrek daun dan dijumpai tumbuh pada pohon Durio sp. Anggrek ini memiliki ciri khas monopodial (tumbuh tegak ke atas), berumpun rapat, berbatang langsing dengan panjang 6-15 cm, lebar 0,1$0,7 \mathrm{~cm}$. Daun tersusun rapat 2 baris (pada tiap baris terdiri atas 15-18 helai anak daun) dengan bentuk daun bulat oval dan helainnya tebal (Yulia, 2007). Pada saat melakukan pengamatan di lapangan ditemukan tidak sedang berbunga, sehingga yang dikoleksi hanya daunnya. Berikut ini beberapa jenis anggrek yang ditemukan di Kawasan TWA Gunung Kelam, khususnya di blok Pemanfaatan.

Jenis-jenis anggrek yang ditemukan tumbuh pada pohon (epifit) dan ditemukan tumbuh di tanah (teresterial) sama banyaknya, yaitu masing-masing 8 jenis. Jumlah jenis anggrek yang ditemukan dalam penelitian ini jauh berbeda dengan hasil penelitian yang dilakukan oleh Ariyanti dan Pa'i (2008) di seluruh 
Keragaman Jenis Anggrek Epifit Sebagai Objek Wisata Alam

Di Kawasan TWA Gunung Kelam Kabupaten Sintang

blok TWA Gunung Kelam yaitu sebanyak 20 jenis, terdiri dari jenis epifit dan tereterial. Berdasarkan penelitian yang dilakukan di blok pemanfaatan ditemukan 16 jenis, antara lain Marga Dendrobium adalah jenis yang memiliki keanekaragaman jenis tertinggi, yaitu terdiri atas empat jenis, sebagaimana ditunjukkan pada tabel berikut.

Tabel1. Jenis-jenis anggrek yang ditemukan di blok pemanfaatan TWA Gunung Kelam

\begin{tabular}{llc}
\hline No & \multicolumn{1}{c}{ Jenis } & Habitus \\
\hline 1 & Apendicula sp & Epifit \\
2 & Arundina graminifolia & Teresterial \\
3 & Ascocentrum miniatum & Teresterial \\
4 & Bulbophyllum auratum (Lindl)Rchb. F & Epifit \\
5 & Bromheadia finlaysoniana (Lindl) Rchb. F & Teresterial \\
6 & Coelogyne sp & Epifit \\
7 & Cymbidium finlaysonianum & Epifit \\
8 & Cymbidium sp & Epifit \\
9 & Dendrobium crumenatum & Epifit \\
10 & Dendrobium secundum & Epifit \\
11 & Dendrobium Smithianum Schltr & Epifit \\
12 & Dendrobium sp & Epifit \\
13 & Grammotophylum speciosum & Epifit \\
14 & Vanda sp & Teresterial \\
15 & Vanda tricolor & Teresterial \\
16 & Tidak teridentifikasi & Teresterial \\
\hline
\end{tabular}

Anggrek banyak ditemukan pada pohon inang dengan ciri-ciri pohon inang batangnya banyak ditumbuhi lumut, tumbuhan anggrek dan liana lainnya. Beberapa jenis
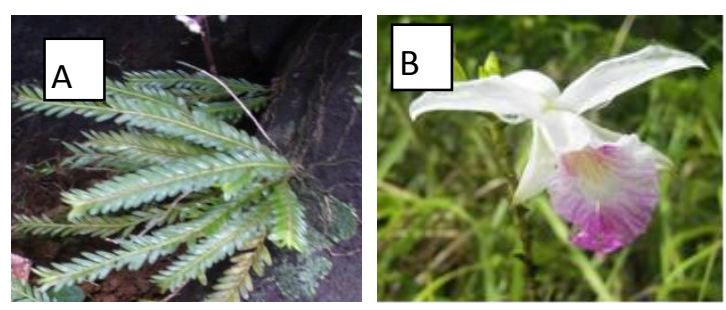

pohon yang dijadikan sebagai inang antara lain Durio sp, Dipterocarpa, Mystaceae dan beberapa jenis lainnya.
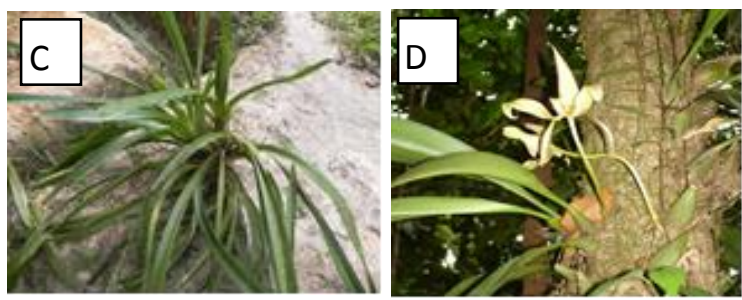

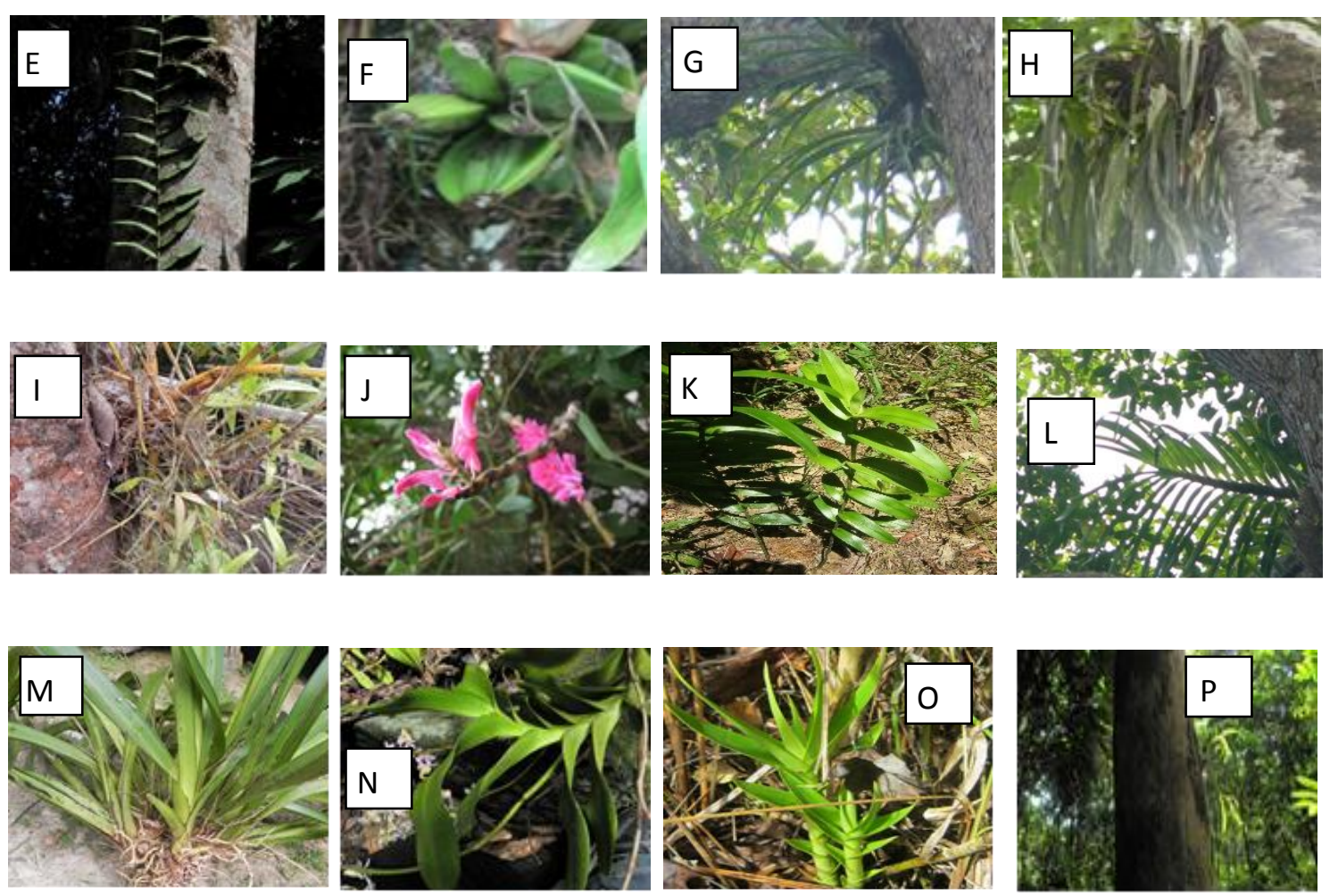

Gambar 1. Jenis Anggrek Yang Ditemukan di Blok Pemanfaatan TWA Gunung Kelam, antara lain A: Apendicula sp; B: Arundina graminifolia, C: Ascocentrum miniatum, D: Bulbophyllum auratum, E: Bromheadia finlaysoniana, F: Coelogyne sp; G: Cymbidium finlaysonianum, H: Cymbidium sp, I: Dendrobium crumenatum Swartz, J: Dendrobium secundum, K: Dendrobium Smithianum Schltr, L: Dendrobium Smithianum Schltr, M: Dendrobium sp, N: Grammatophylum speciosum, O: Vanda sp, P: Vanda tricolor, Q:

Jenis anggrek yang paling menarik ditemukan di Kawasan TWA Gunung Kelam, sehingga sangat menarik untuk diamati sebagai objek dan daya Tarik wisata alam, khususnya wisata pengamatan flora langka dan menarik, antara lain:

Dendrobium secundum (B1.) Lindl.

Anggrek ini disebut juga sebagai anggrek sikat atau anggrek kesumba (Ariyanti dan Pa'i, 2008). Bunganya tumbuh di satu sisi tangkai bunga yang panjangnya kurang lebih $10 \mathrm{~cm}$. Bunga warna ungu muda, merah muda atau kadang-kadang putih. Batangnya selebar jari telunjuk. Kondisi hutan tempat ditemukannya anggrek ini relatif bagus sehingga memiliki banyak naungan, karena anggrek ini memerlukan cahaya matahari pada kisaran sebesar 50\% (Ariyanti, 2008).

Grammatophyllum speciosum $\mathbf{B l}$. 
Keragaman Jenis Anggrek Epifit Sebagai Objek Wisata Alam

Di Kawasan TWA Gunung Kelam Kabupaten Sintang

Anggrek ini juga dikenal Dendrobium Smithianum Schltr,

sebagai anggrek macan, di Coelogyne sp.

Kalimantan Barat dikenal sebagai anggrek tebu (Ariyanti dan Pa'i,

\section{DAFTARPUSTAKA}

2008) dengan beberapa sinonim: $G$.

macranthum (Wight.) Rchb.f.,

Pattonia macrantha Wight., $G$.

Antonius, Suman, A. Leksono, A.L., fastuosum Lindl., G. wallisii Rchb.f.,

G. giganteum Bl. ex Rchb.f. Jenis ini mempunyai bunga yang tahan lama, besar dan menarik, sepal dan petalnya mempunyai bercak coklat yang menarik. Penyebaran jenis ini di Kalimantan cukup luas meliputi hutan dataran rendah tropis. dan Riniwati, H. 2018. Ecotourism Management Strategy of Peat Swamp Forest in Baning Nature Tourist Park Area in West Kalimantan Indonesia. IOSR Journal of Business and Management. Volume 20. PP 78-83.

\section{KESIMPULAN}

Sebanyak 16 jenis anggrek ditemukan selama lebih kurang 2 bulan penelitian (10 Februari sampai dengan 21 Maret 2020). Jenis Anggrek yang ditemukan adalah jenis Bromheadia finlaysoniana (Lindl) Rchb. F., Dendrobium sp,; Ascocentrum miniatum, Arundina graminifolia, Vanda sp, Vanda tricolor, Grammatophylum speciosum, Dendrobium crumenatum Swartz, Dendrobium secundum, Bulbophyllum auratum (Lindl) Rchb. F, Cymbidium finlaysoninum, Antonius, Suman, A. Leksono, A.L., dan Riniwati, H. 2018. Nature potentials and implication for ecotourism development in sintang regency West Kalimantan Indonesia Eco. Env. \& Cons. 25 (1).pp. 178-185.

Ariyanti, E.E., dan PA'I, 2008. Inventarisasi Anggrek di Kabupaten Sintang, Kalimantan Barat. Jurnal Cymbidium sp, Apendicula sp, 
Biodiversitas. 9 (1): 2124.

Effendi, S., Ariyanti, N.S., dan Chikmawati, T., 2019.

Keanekaragaman dan

Kelimpahan Anggrek

Epifit di Kaki Gunung

Liangprang Kalimantan

Timur. Jurnal Ilmu-Ilmu

Hayati. Volume 18

(3):305-3014.

Irawati, 2002, 'Pelestarian jenis anggrek di Indonesia', Proseding Seminar Anggrek Nasional, Yogyakarta.

Lestari, L.D., Rafdinal dan Mukarlina. 2019. Inventarisasi Jenis Anggrek (Orchidaceae) Di Taman Wisata Alam Bukit Kelam Kabupaten Sintang. Jurnal. Protobiont. Volume 8 (3):46-52.

Schuiteman, A. and E.F. de Vogel. 2002. Flora Malesiana: Orchids of New Guinea vol. II. UNESCO Publishing, CDROM.

Schuiteman, A and E.F.de Vogel. 2007. Orchidaceae of Papua. In: Marshall AJ, Beehler BM (Eds). The Ecology of Papua. Part One. The Ecology of Indonesia Series VI. Periplus Ed. (HK) Ltd. Singapore.

Siregar, C, Listiawati, A, \& Purwaningsih, 2005, Anggrek Spesies Kalimantan Barat Vol. 1. Pontianak, Lembaga Penelitian dan Pengembangan

Pariwisata Kalimantan Barat (LP3KB).

Vollering, J., A. Schuiteman, E.F. de Vogel, R. van Vugt, and N. Raes. 2016. Phytogeography of New Guinean orchids: Patterns of species richness and turnover. Journal of Biogeography.43:204214. 
